\title{
Social Problems Caused by Undercover Marketing and Social Media Traces in Japan
}

\author{
Makoto Sakai \\ Ph.D. Media and Governance \\ Lecturer, Bunkyo University, Tokyo, Japan \\ wayne80@shonan.bunkyo.ac.jp
}

\author{
Doi:10.5901/ajis.2013.v2n3p319
}

\begin{abstract}
According to Sigmund Freud's thesis "The Ego and the Id," it is difficult for humans to control our desires consciously, but it is easy for us to be influenced by other people's desires unconsciously(Freud 1990). For example, to take on other people's desires is similar to adjusting to an established order or to sharing a sense of community. Therefore, successful advertisements or recommendations must imply popularity. However, if advertisements and others' recommendations somehow lose their credibility, how does our desire unconsciously change? Undercover marketing has recently become popular on Japanese websites. To take just three examples from 2012, a celebrity made a pseudo-advertisement blog; the most famous restaurant ranking site was found to have manipulated its rankings; and the most famous cosmetics distribution site hired people for working to artificially raise evaluation scores. Simultaneously, social media has begun gathering large amounts of personal data to use for undercover marketing. In this thesis, I compare undercover marketing in Japan today with a similar phenomenon from the classical marketing history of Japan, called Sakura, a doughnutter, or faking. Then I discuss how this new type of undercover marketing creates new human rights problems, such as regarding protecting personal information and the right to be forgotten on websites. I conclude that undercover marketing online represents a change in the unconscious world order that the modern economic system has built up over time.
\end{abstract}

Keywords: media studies, sociology, information society

\section{Introduction}

New programs are designed in such a way that they allow you to start conversations with potential lovers on dating sites, in order to gather personal information. Certain online behavior compromises personal information such as sexual preference, menstruation cycle, annual income, criminal record, and so on. We are living in a world where our most intimate details are used for marketing products and brands to us, without our knowledge. We can now have comfort and convenience in our information environment depending on our individual desires. However, what risks are we taking in return?

According to Sigmund Freud's thesis "The Ego and the Id," it is difficult for humans to control our own desires consciously, but it is very easy for humans to imitate and be influenced by other people's desires unconsciously. Practically, if we had only original desires without being influenced by others, advertisements and brand-name products would not exist. In addition, even the person who usually avoids brand-name products may still buy them as gifts.

How media is successfully supported by advertising revenue can be understood through a simple law, that people imitate the desires of others, which Freud asserted was at the base of all our consumption. We are living in a world of fashion and social order that originally included deviation or ambiguity, while reading a flow of the desires of others. However, when the desires of another person turn out to involve trickery or cheating, and they are so pervasive that they supersede people's true desires, what will happen?

We cannot only join a fashion in imitation of desires of another person, but also we cannot come to believe that social order exists on the faith of others. Recently, stealth marketing has not only caused problems in business manners, but also related to the modern social order that built the desires that we imitate in the first place.

\section{The Definition of Undercover Marketing and Examples in Japan}

It is necessary to provide a clear definition of undercover marketing. There are variations from the classic technique popular in the Edo era and governed by samurai (from 410 years ago to 150 years ago), to modern innovations in information technology. Undercover marketing is also called stealth marketing, as the advertising may appear to 
consumers as some other form of communication. Stealth marketing is a highly developed technique of cheating that often escapes the notice of tens of millions of online users. It is named after famous fighter planes that can avoid radar detection-the Stealth fighter. If a cheating company has been discovered, it loses trust, so it is a risky choice for advertising companies.

For example, a scandal erupted in Japan around stealth marketing practices at a popular restaurant ranking site, tabe-log (tabe means eating), in January 2012. An in-house investigation revealed that 39 stealth marketing companies had made word-of mouth contributions, raising their ranking artificially. Thus, they increased the number online visitors intentionally. Around the same time, one stealth marketing company recruited and paid rewards to people for working to artificially raise evaluation scores for specific products for @ cosme, Japan's most famous word-of-mouth cosmetics site,. Just after that in "yahoo chie-bukuro" (yahoo Q and A in English), one restaurant in Tokyo national airport was found to have asked a stealth marketing company to create fake questions and answers to draw customer interest. Therefore, I think 2012 should be called the year of stealth marketing in Japan.

In addition, celebrity were criticized for blogging and Tweeting about specific products in return for rewards. In September 2011, two popular talents had written similar comments on their blogs recommending the same tooth powder, "Clear Clean" from Kao. The deception surfaced because an advertisement company had directed them to post almost the same sentence to promote the same product. Because celebrities can earn rewards from hundreds of thousands to millions of yen (between about 1,000 and 10,000 US dollars) per endorsement, they accept the risks of this cheating (we use the slang term sakura in Japanese) on the agreement. Advertisers have come to see traditional media as costineffective, so stealth marketing has gained popularity.

Stealth marketing became controversial in the U.S. around 2005. In Japan, I examined five databases of popular newspapers and found the first mention in an article on October 24, 2005, in the Sankei Business Eye that discussed the popularity of stealth marketing in the U.S. ${ }^{1}$ Since 2006 , in Japan, these advertisements have gained popularity mainly for their high value-added products such as healthy foods, cosmetics, and hair restorers. According to a company analyzing word-of-mouth data, sakura appeared online conspicuously around 2006, and the reliability of the analysis decreased depending on sites that use word of mouth, such as the cosmetics selling site. In any case, the acknowledged or revealed stealth marketing and cheating using sakura will be only the tip of the iceberg now.

\section{The Social Risks of Undercover Marketing}

Stealth marketing in general will be considered an expensive technique from now on unless strict regulation is implemented. An initial investment of around 1 million yen (about 10,000 US dollars) in Japan will yield not only the homepage setup for the shop but also management of the online word-of-mouth campaign, and even secure a number of home page views, and all of the work can be sent to the stealth marketing company. Certain companies provide not only restaurant or cosmetics rankings but also Facebook "Likes" and Twitter re-tweets. Thus, the services have already diversified. When one Japanese politician bought Facebook "Likes" from stealth marketing companies for the Upper House election of 2013, most Likes came from Turkey., He failed to win a seat, but found himself in a great controversy².

In addition, writers who have not achieved success in publication media have engaged in stealth marketing jobs, such as writing exaggerated comments, so it becomes difficult to distinguish between the comments of the consumers and professional stealth marketing writers. In other words, it is now possible to buy reputation on the web, and the implications must be considered.

The stealth marketing phenomenon is not peculiar to the web. Similar forms of cheating can easily be found in the articles of some newspapers, magazines, and news sites affiliated with newspaper publishers in Japan, and it even seems possible to buy articles at relatively low prices. Nor is it hard to find examples of make-believe on television. In addition, television stations repeatedly broadcast the songs for which they possess the rights, which, as a business model, has produced huge broadcast advertisement income. In Japan, this type of business model has been called "match pump style," referring to the same person starting a fire and then extinguishing it.

The classic and still fashionable technique is to make fashions and trends seem accidental. For example, one stealth marketer advertised a new product for McDonald's during Christmas of 2008. This company employed a large number of part-timers for an hourly wage of 1,000 yen (about 10 dollar) to stand in a long line on the street to create the

\footnotetext{
${ }^{1}$ The Sankei Business Eye, October 24, 2005

2 The Mainichi newspaper, July 22, 2013
} 
illusion of demand. In other words, stealth marketing is not a new business model, but it incorporates some classical cheating techniques that have been used in traditional media and advertising agencies. Therefore, it is not fair to criticize only online ranking sites and the word-of-mouth sites that contract with stealth marketing agencies. These are only newcomers, so we should remember the origins of stealth marketing. Not all old advertising practices were preferable to the new ones.

It is said the word sakura has its origins in the fake customer who went into a Japanese playhouse and raised a false shout of joy in the Edo era (from 410 years ago to 150 years ago). This technique in itself is not so different in the era of the Internet. Make-believe advertisement and stealth marketing might grow even as newspaper and magazine circulation drops, and online and television advertisement revenue falls away.

\section{Regulation of Undercover Marketing}

It is an international standard in the media to clearly distinguish advertisement from editorial content. For example, advertising by word of mouth while offering constant rewards for posing as a customer in the U.S. can draw the attention of the Federal Trade Commission. Stealth marketing is called "undercover marketing" in the U.S. and is similar to "viral marketing" and "buzz marketing" from the past. In any cases, companies are required to label the advertisement if they perform stealth marketing with a reward from a supplier.

In Japan in 2011, the Consumer Affairs Agency announced an initiative regarding "the problems and caution in advertisement identification to affect Internet consumer business." However, this intention does has no legal force. Of course, it is regulated by a premium notation about the act that provoke speculative spirit and the advertisement that are different from facts definitely in Japan. However, it is impossible to restrict to the writing of stealth marketing articles even if the marketers admit they are fake. Compliance is the responsibility and discretion of the site manager. The issue of stealth marketing is considered a problem only of technique by the business community, due to the generous regulations, rather than a recognized threat to the social order.

Jean Baudrillard states that an advertisement is directed like the sexual play of a pornographic film (Baudrillard 1995). As he says in "Simulacra and Simulation," even if it is sakura or stealth marketing, an advertisement will be created with a vague appearance on the border between reality and fiction. Moreover, this is more likely to become the advertising mainstream in the future. Therefore, we should prepare for the possibility that stealth marketing will be used not only for business but also for the political or religious reasons.

In China, for example, access to political and sexual content is restricted for some websites. On the other hand, stealth marketing events called "go-mou parties" serve to guide online arguments in the desired direction of the Chinese Communist Party, in exchange for payment. They develop political propaganda online, night and day, at the rate of gomou (about 16 cents) per positive comment for the Party. Specifically, when criticism of the Party increases, like after a 2011 railway accident, and the 2012 arrest of Chongqing city leader Bo Xilai, a, people at go-mou parties wrote comments and articles to counteract criticism of the Party on the Chinese versions Twitter, Weibo and QQ. They have deflected the criticism to others, such as to the Japanese government. Now it is said that their guarantee has appreciated to approximately 1 yuan per comment. Of course, Japan is a different social environment from the one-party rule in China, and we should remember that stealth marketing is not only for business but can be used in politics and religion. Regulation of undercover marketing will be necessary especially in these areas.

\section{The Secondary Uses of Personal Information for Undercover Marketing}

In addition to stealth marketing, we should think about all the risks to our personal information as it begins to flow into unexpected places for marketing via the web. For example, I consider the technique of behavioral retargeting advertisement to be a kind of stealth marketing, depending on how personal information is handled. This technique has already been generalized on the web, and I think the range of personal information used for marketing will increase from now on.

When we search for information online, our user information and search history are saved in a form that is available to administrators for analysis through cookies. For example, we can open a page and log in automatically after logging onto Twitter once. In addition, we can view recommended products based on a purchase history from when we visited the shopping site in the past. Cookies save personal information or the reading history of the site. The expiration date of the data in the cookie varies according to site policy, and it is said to be two years in Google, 30 days in Rakuten ( a popular Japanese shopping site), 24 hours in Amazon. If this preservation period is long, personal data recorded by 
cookies will be used longer for advertisement and marketing purposes.

For example, if we search for high value-added product names or company names such as luxury apartment builders, credit card companies, study-abroad intermediaries, and high-quality medical services, we will be shown the same advertisements according to Google contracts with news sites and personal blog for a long term. In other words, as long as the search history is saved, user who have searched for specific words are locked in as the customers who are more likely to purchase specific products and services. In addition, search histories have generally been used for marketing even if we do not shop online. Google business product manager Tom Leung said that 97 to 98 percent of users return to shopping sites without buying anything, but the site operator can earn enough profit by using or selling the customer's search history for advertisement and marketing ${ }^{3}$.

The value of the search history may be high depending on products, because so many products are difficult to buy online without face-to-face contact with a salesclerk. For example, the obstetrics and gynecology department can perform effective business if they have addresses and names that searched for pregnancy information online. The company selling wigs or hair restorers can mail free coupons to possibly gain new customers if they know have search histories about these products. It is said that some companies will sell their personal information just before bankruptcy, instead of selling products or services to earn more. Considering these facts, is regulating about the resale of such personal data necessary?

On Facebook, advertisements narrowly targeted to location, age, interest, and so on have already been put to practical use. The user's friends who have already registered appear as advertisement and recommendation for some products, which is a different technique from the same old advertisement. Facebook requires little personal information at the time of enrollment, but as we repeat communication inside the closed system, Facebook gathers various information such as friend relations, credit card numbers from purchases via the site, access locations, university attended, and so on.

In addition, this story is not limited to Facebook, but photographs online are also a treasure house of personal information. For example, the text containing positional information, called the Exif, is recorded as data when we take a photograph with a smartphone. Thus, even if a photographer does not input an address, it is easy to register the location of some photographs and identify the home address or the range of daily activities.

In addition, it is already possible for faces to be captured from uploaded photographs and analyzed to discover who was with whom, where, and when, from surveillance cameras. If at least ten images exist of one face, current techniques make it possible to extract a user's face fingerprint, according to Eric Schmidt of Google (Auletta 2009). If such face fingerprints are compiled into a database that links with networked surveillance cameras, it is possible to record the daily activities of people on the streets from surveillance cameras.

\section{To prevent the Use of Biometric Information for Undercover Marketing}

The risk is great that personal information can be acquired by a smartphone. Applications with many users often have gathered unnecessary personal information such as telephone books, e-mail address lists, saved photographs, call histories, and positional information based on legal agreements. While many convenient applications exist and are free to use, we should not forget the personal information we are giving up to earn this convenience.

Besides GPS functions, acceleration sensors are also built into smartphones. If we can analyze the data gathered, we can understand who is where and how fast they are traveling, where they stop, and what they see. Future wearable devices like Google Glass will spread and, as Sigmund Freud said, "The flow of the desire of the individual person" will be analyzed unconsciously in much more detail than smartphones have made possible now. Attached and embedded devices will evolve, and begin to gather not only basic information such as blood pressure or pulse, but also metastasis of cancer cells or the probability of senility, and we will monitor it all in real time. In this future, we will not only benefit from the ability to monitor ourselves, but also we will be at risk of being monitored by others. For example, when our physical condition deteriorates suddenly, we may see an advertisement for a magic bullet against cancer and instantly understand our disease.

We have already stepped into the time when such advanced services will be provided. From Google and Facebook to porn sites, companies analyze behavior and search history and use the results for advertising and marketing. That is how these popular sites can provide high-quality services for free. We should thus understand that when we use a

\footnotetext{
${ }^{3}$ Impress Business Media web-tan, February 4, 2008
} 
website freely, our personal information has been sold for secondary uses without our knowledge. A Japanese proverb suits the present undercover marketing society, "the most expensive things sell for nothing." To conclude, online undercover marketing signifies a change in the unconscious world order that the modern economic system has built over time.

To return to Freud's words at the beginning, in the modern era, we have built up a social order of imitation of the desires of others. Now, we have begun to imitate desires that have been created artificially through undercover marketing. In Japan, we deride indiscriminate imitation without reflection. From another point of view, no matter how information technology develops, I think to some extent our desires will not have evolved so much from the level of indiscriminate imitation, as in the Edo-Samurai era. Thus, I think the unconscious world order has already changed, but on the other hand, some of the same old regulations of undercover marketing will be needed in future.

\section{References}

Auletta, K. (2009). Googled: The end of the world as we know it. New York: Penguin Press HC

Baudrillard, J. (1995) Simulacra and simulation (The body, in theory: Histories of cultural materialism). Michigan: University of Michigan Press.

Freud, S. (1990). The ego and the id. New York : W. W. Norton \& Company.

Impress Business Media web-tan, February 4, 2008

The Mainichi newspaper, July 22, 2013

The Sankei Business Eye, October 24, 2005 
